\title{
SEGREGATION OF BIVALVES AND BRACHIOPODS IN THE UPPER PALEOZOIC: THE INFLUENCE OF ECOLOGY ON MACROEVOLUTIONARY HISTORY
}

OLSZEWSKI, Thomas D., Department of Geosciences, Pennsylvania State University, Deike Building, University Park, PA 16802 , U.S.A.

A classic example of biotic replacement in the fossil record is that of articulate brachiopods by bivalves in shallow marine, level-bottom communities. Tabulation of the diversity of each of these clades through time, however, has shown that this is not an example of gradual competitive displacement of one group by another. Rather, bivalves and brachiopods were "ships that passed in the night" and the pattern of change-over is the result of how each group responded to the endPermian mass extinction. On the other hand, empirical studies have shown that these two groups share many of the same resources and that interspecific competition could take place if individuals from each group co-occurred in the same environment. On the microevolutionary scale, species do react to such competition (recorded as niche partitioning), and bivalves and brachiopods are excellent candidates for such a process. The documented history of these two groups requires either that micro-scale competition was occurring but is masked by macro-scale pattern or that direct competition was prevented from occurring.

Initial results of reciprocal averaging of data from rocks straddling the Pennsylvanian-Permian boundary in the northern Mid-Continent of North America show a strong segregation in the occurrence of bivalves and articulate brachiopods. The data consist of taxon lists of collections from specific beds at specific locations (32 genera, 237 collections). Depositional environments range from coastal paralic to shallow open-marine. The figure clearly shows that bivalves are more likely to occur with other bivalves than with brachiopods and vice-versa. In fact, this separation was recognized by previous investigators and used to help define biofacies. There is at least partial

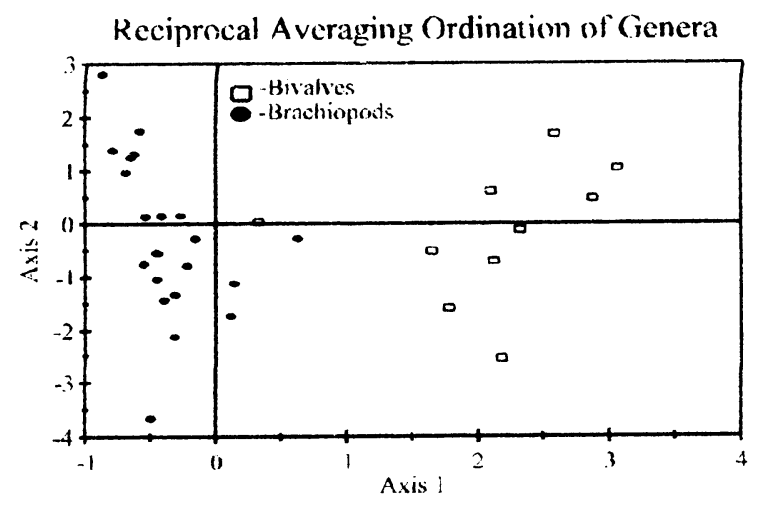
mediation of the pattern by environment, as bivalves are more tolerant of conditions that are hostile to brachiopods (temperature and salinity variations, for example). This explains why brachiopods are absent or rare in some collections but fails to clarify why bivalves are absent or rare in some environments that should have been inhabitable to them.

This pattern implies that real differences existed in the paleoecology of bivalves and articulate brachiopods and that their post-Paleozoic history may not simply reflect the vagaries of chance during recovery. After the extinction event, bivalves came to dominate environments that had previously been the domain of articulate brachiopods. If they always had the ability to occupy these environments, it is possible that they were prevented from doing so by some sort of ecological incumbency mechanism favoring brachiopods. Disruption of such a mechanism during the endPermian extinction may be what allowed bivalves to occupy habitats previously dominated by brachiopods. It is conceivable that the different degree of extinction in these two groups during this event and the pattern of recovery afterwards were influenced by selective habitat destruction with favor being shown on the habitats already occupied by bivalves. 